\title{
RADIOLOGICAL SIGN OF RECURRENT DISLOCATION OF THE PATELLA
}

\author{
A. McDougall and J. Douglas Brown, Glasgow, Scotland \\ From the Orthopaedic Department, the Victoria Infirmary of Glasgow
}

The diagnosis of recurrent dislocation or subluxation of the patella is easy if the patient is seen with the patella dislocated. When the displaced patella reduces itself spontaneously, or with assistance, the observant patient may be able to describe in detail the sequence of events, and in these cases the diagnosis is made without difficulty. Often, however, the problem is that of a young person brought from the field of play with a painful swollen knee. There has been a twisting injury to the knee accompanied by acute pain along the inner side of the joint; something is felt to go out of place, and the knee locks. The patient takes a few steps and the knee straightens giving a sensation of unlocking. It is difficult to distinguish this story from that of locking caused by a tear of a meniscus (Watson-Jones 1941, Ellis 1954). In two out of three cases of dislocation of the patella reported by Coleman (1948) a diagnosis of torn medial meniscus had been made previously. Stonham (1954) reported that the symptoms of subluxation of the patella might be ascribed to displacement of the lateral meniscus. This in our experience has not been common, the medial cartilage being blamed more often.

Coleman (1948) described two cases of what he termed recurrent osteochondral fracture of the patella. In these the medial border of the dislocating patella had been caught by the edge of the lateral femoral condyle and part of the articular cartilage of the patella had been broken off with a thin layer of underlying bone, the detached fragment forming a loose body.

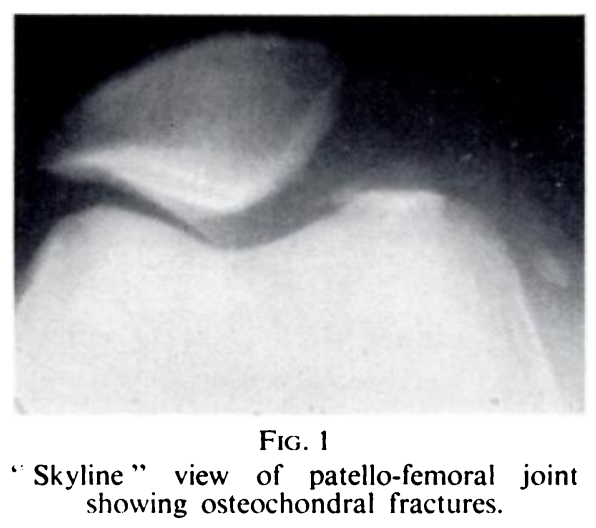

Coleman pointed out that the presence in the joint of this particular type of loose body was diagnostic of recurrent dislocation of the patella, that it might not be seen in routine anteroposterior and lateral radiographs of the knee, and that "skyline" views were essential. Since reading this article we have always taken tangential views of the knee when there has been a history of "locking" after an injury. On a number of occasions the lesion described by Coleman has been present (Fig. 1).

A young woman sustained a twisting injury of the knee, which "locked"; she attended hospital, a tear of the medial cartilage was diagnosed and her name was placed on the waiting list for operation. While she was waiting for admission the knee "locked " on several occasions and when she was called up for review before admission radiographs were taken. The routine antero-posterior and lateral views could be passed as within normal limits but the "skyline" view showed Coleman's osteochondral fracture (Fig. 1) which indicated that the lesion was in fact recurrent dislocation of the patella. 
Although we recognise the importance of Coleman's observations, we believe that there is a much more common and more reliable radiographic lesion in recurrent dislocation of the patella-namely, the presence of one or more small bony ossicles on the medial side of the patella. These ossicles take several forms: they may be single and discrete, or multiple (Figs. 2 and 3). Sometimes there is a thickening of the inner border of the patella in the form of an exostosis (Fig. 4). In all our patients who presented this radiographic appearance the

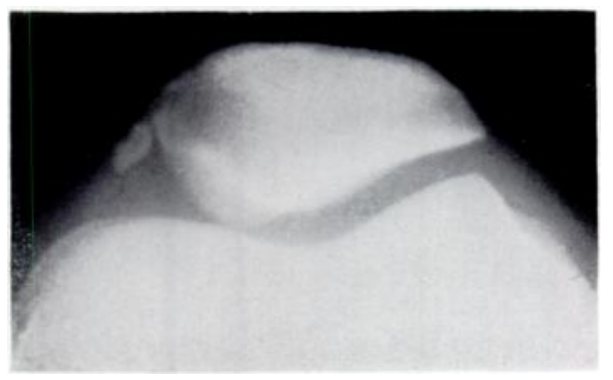

FIG. 2

Single bony ossicle on medial side of patella.

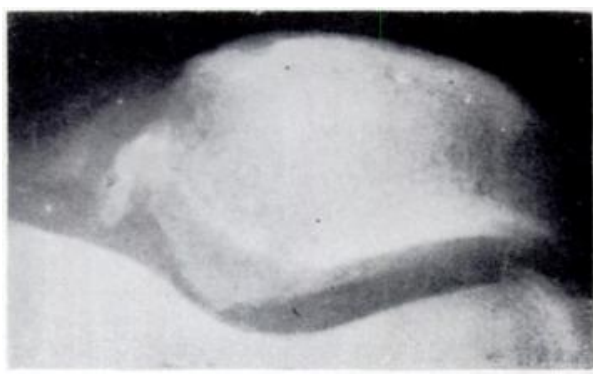

FIG. 3

Multiple irregular bony ossicles.

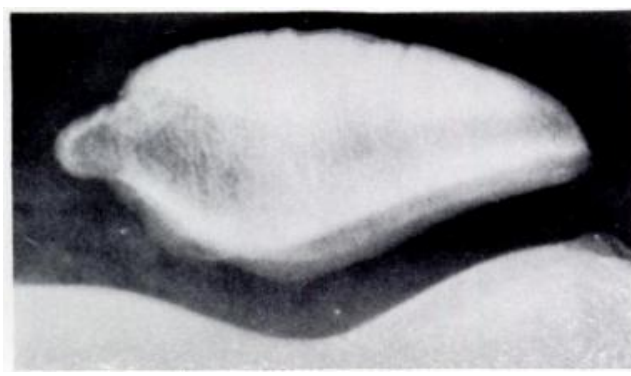

Fig. 4

Exostosis on medial border of patella.

diagnosis was proved to be recurrent dislocation or subluxation of the patella, and we regard the changes as diagnostic. In fourteen cases of recurrent dislocation of the patella the following lesions were found: in nine there were ossicles at the medial side of the affected patella; three had osteochondral fractures, and in two there was no evidence of any bony change.

\section{ILLUSTRATIVE CASE REPORT}

In July 1965 a youth aged nineteen years fell and injured his right knee while playing football. So far as he could recollect, another player fell on the leg. The knee felt stiff, but after he stamped the foot on the ground something went into place. He had pain and swelling of the joint, the tenderness being most marked along the medial border of the patella. The knee continued to cause trouble, and in September 1965 he was admitted to hospital. At operation the medial compartment of the knee was explored; the records state that no abnormality was found in the medial cartilage, which was removed. He attended the hospital until March 1966 when he was discharged. He was seen by us in December 1967 complaining that for six months he had experienced something jumping out of place in the knee and that this sensation was accompanied by the original pain along the medial border of the patella. A radiograph showed a bony ossicle, confirming the diagnosis of recurrent dislocation of the patella.

At operation the small ossicles are found deep to the periosteum on the medial side of the patella. They are caused by ossification in a haematoma formed when the medial quadriceps expansion tears the periosteum from its patellar attachment as the patella 
dislocates laterally. The lesion is analogous to others in which a ligament or tendon is avulsed from its insertion, as in the Pelligrini-Stieda lesion (Stieda 1905) and the Sinding-LarsenJohansson lesion (Sinding-Larsen 1921).

A search of the literature revealed two references to bony lesions associated with recurrent dislocation of the patella. Macnab (1952) described a small loose body in relationship to the medial edge of a patella which had been excised for recurrent dislocation; and Blunden (1953) indicated that a detached ossicle on the medial side of the bone was often found in radiographs of recurrently subluxating patellae.

Because the ossicle is formed by ossification in a haematoma, it is not found immediately after injury but only when sufficient time has elapsed. Its absence in radiographs taken soon after injury does not therefore rule out a diagnosis of dislocation of the patella.

\section{SUMMARY}

1. Attention is drawn to the importance of taking tangential radiographs of the patella in all cases of injury to the knee, especially when there is difficulty in distinguishing between recurrent dislocation of the patella and tear of a meniscus.

2. New bone formation along the medial side of the patella confirms a diagnosis of recurrent dislocation.

3. The importance of Coleman`s original observations is stressed.

\section{REFERENCES}

Blunden, R. (1953): Recurrent Dislocation of Patella. Journal of Bone and Joint Surgery, 35-B, 507.

Coleman, H. M. (1948): Recurrent Osteochondral Fracture of the Patella. Journal of Bone and Joint Surgery, 30-B, 153.

Eluis, J. S. (1954): Primary Dislocation of the Patella. Journal of Bone and Joint Surgery, 36-B, 145.

MACNAB, I. (1952): Recurrent Dislocation of the Patella. Journal of Bone and Joint Surgery, 34-A, 957.

Sinding-Larsen, C. M. F. (1921): A Hitherto Unknown Affection of the Patella in Children. Acta Radiologica, $1,171$.

StiedA, A. (1905): Ueber eine typische Verletzung am unteren Femurende. Archiv fïr klinische Chirurgie, $85,815$.

Stonham, F. (1954): Recurrent Dislocation of the Patella. Journal of Bone and Joint Surgery, 36-B, 155.

Watson-Jones, R. (1941): Fractures and Other Bone and Joint Injuries. Second edition, n. 555. Edinburgh:

E. \& S. Livingstone. 